\title{
ANALISIS TINGKAT KEMATANGAN PENDISTRIBUSIAN RUANG KELAS DENGAN FRAMEWORK COBIT 4.1 MENGGUNAKAN DOMAIN DS10
}

\author{
Imroatul Muthoharoh ${ }^{1}$, Elfara Fraksi Dwipa ${ }^{2}$, Renny Sari Dewi ${ }^{3}$ \\ 1,2,3Fakultas Teknologi Industri dan Kreatif, Universitas Internasional Semen Indonesia \\ Email: 1imroatul.muthoharoh15@student.uisi.ac.id, ${ }^{2}$ elfara.dwipa15@student.uisi.ac.id, ${ }^{3}$ renny.dewi@uisi.ac.id
}

(Naskah masuk: 28 Desember 2018, diterima untuk diterbitkan: 04 November 2019)

\begin{abstract}
Abstrak
Audit TI adalah bentuk suatu pengendalian atau pengawasan dari infrastruktur teknologi informasi yang dilakukan meliputi keseluruhannya, atau secara singkat dapat dikenal sebagai proses evaluasi dari semua kegiatan TI dalam organisasi. Auditor TI adalah orang yang melakukan audit, yang memiliki tugas yaitu mengumpulkan bukti-bukti melalui wawancara, survei, observasi, dan review dokumentasi. Terdapat dua macam data, yaitu data primer dan data sekunder. Data primer diperoleh melalui observasi atau wawancara, sedangkan data sekunder diperoleh dari jurnal ilmiah, e-book, dan lain-lain. Alur penelitian yang akan dilaksanakan dalam pengelolaan masalah pendistribusian kelas di UISI (Universitas Internasional Semen Indonesia). Hasil yang didapatkan adalah nilai compliance 8.125 persen dan maturity level yang berada di tingkat 1 yaitu senilai 1.6 (skala 5). Hal ini menunjukkan bahwa UISI masih belum memanfaatkan TI dengan baik dan secara maksimal.
\end{abstract}

Kata kunci: tingkat kepatuhan, tingkat kematangan, ruang kelas, COBIT 4.

\section{MATURITY LEVEL MEASUREMENT CLASSROOM DISTRIBUTION USING COBIT 4.1 WITH DOMAIN DS10}

\begin{abstract}
IT audit is a form of control or supervision of the information technology infrastructure that is carried out covering the whole, or briefly can be known as the evaluation process of all IT activities in the organization. IT auditors are people who conduct audits, who have the task of collecting evidence through interviews, surveys, observations, and documentation reviews. There are two types of data, namely primary data and secondary data. Primary data is obtained through observation or interview, while secondary data is obtained from scientific journals, e-books, and others. The flow of research that will be carried out in the management of class distribution problems in UISI (University International of Semen Indonesia). The results obtained are 8.125 percent compliance value and level 1 maturity level which is worth 1.6 (scale 5). This shows that UISI still does not utilize IT properly and optimally.
\end{abstract}

Keywords: maturity level, compliance, classroom, COBIT 4.

\section{PENDAHULUAN}

Hampir seluruh organisasi menggunakan Teknologi Informasi untuk keberlangsungan proses bisnis yang dimiliki. Organisasi yang baik mengetahui bahwa TI dapat meningkatkan nilai dalam aktivitas utama maupun aktivitas pendukung. Saat ini tidak hanya organisasi atau perusahaan yang menerapkan TI, akan tetapi institusi pendidikan menggunakan TI untuk mendukung kinerjanya.

Universitas Internasional Semen Indonesia adalah salah satu institusi pendidikan yang menerapkan TI dalam proses operasionalnya, contohnya adalah sistem informasi akademik, sistem poin ekstrakulikuler mahasiswa, sistem perpustakaan, dll. Berdasarkan wawancara dengan layanan akademik UISI, masih ada beberapa layanan yang masih memiliki masalah karena belum memiliki sistem TI. Salah satu masalahnya adalah dalam pendistribusian ruang kelas sesuai dengan permintaan program studi. Pihak layanan akademik masih melakukan semua prosesnya dengan cara manual yang seharusnya bisa diefisienkan dengan menggunakan TI. Layanan akademik UISI masih melakukan komunikasi langsung untuk permintaan ruang kelas sehingga masih sering mengalami misscomunication antar layanan akademik dan program studi. Keberadaan TI dalam organisasi harus dipelihara, dinilai, dan dievaluasi dengan baik agar 
dapat dipastikan alur organisasi tetap inline dengan tujuan di organisasi tersebut. Untuk memastikan alur dan tujuan organisasi tetap sejalan, maka dilakukan audit TI.

Audit TI merupakan bentuk pengendalian dan pengawasan dari infrastruktur TI secara menyeluruh. Audit TI terdapat kegiatan pengawasan, penilaian, dan evaluasi. Auditor TI adalah orang yang melakukan audit, dengan cara mengumpulkan buktibukti melalui survei, wawancara, observasi, dan review dokumentasi. Audit TI dapat dilakukan menggunakan berbagai framework seperti COBIT, COSO, ITIL, dll.

COBIT (Control Objectives for Information and related Technology) adalah framework untuk melakukan audit TI. Framework COBIT memiliki 4 domain yaitu Plan and Organise (PO), Acquire and Implement (AI), Deliver and Support (DS), dan Monitor and Evaluate (ME).

DS10 adalah salah satu sub-domain dari domain Deliver and Support (DS). DS10 akan membahas tentang Manage Problems atau Pengelolaan masalah.

Berdasarkan penjelasan permasalahan di paragraf sebelumnya, maka dalam penelitian ini akan mengusulkan untuk meneliti dan menilai/melakukan pengukuran tingkat kematangan pendistribusian ruang kelas berdasarkan permintaan program studi, serta melaporkan dalam bentuk laporan temuan dan rekomendasi dalam domain DS10 dalam framework COBIT 4.1. Penelitian dibatasi dengan satu sub domain yaitu DS10 dengan justifikasi pembagian area penelitian.

Penggunaan objek penelitian pendistribusian ruang kelas, dikarenakan melihat pada prioritas studi kasus pada ruang lingkup yang sesungguhnya di universitas, karena universitas memiliki jurusan dengan multi disiplin ilmu yang beragam dengan adanya ciri khas karakteristik pembelajaran dari masing - masing program studi. Karakteristik Sosial mengutamakan penggunaan kelas dalam bentuk melingkar dan bersifat untuk berdiskusi atau berinteraksi secara sosial, karakteristik Eksak mengutamakan penggunaan kelas dalam bidang ilmu pasti, karakteristik TI mengutamakan penggunaan kelas dalam bidang teknologi yang membutuhkan komputer.

\section{METODE PENELITIAN}

Berdasarkan paparan studi kasus yang akan diambil, maka dalam penelitian ini akan menggunakan metode kualitatif dan kuantitatif dimana penelitian yang diambil akan mengeluarkan hasil berupa angka dan deskripsi tentang hasil yang didapatkan.
Tabel 1. Penelitian terdahulu COBIT 4.1

\begin{tabular}{|c|c|c|}
\hline penulis & judul & celah \\
\hline $\begin{array}{l}\text { (Wardani dan } \\
\text { Puspitasari, } \\
\text { 2014) }\end{array}$ & $\begin{array}{l}\text { Audit Tata } \\
\text { Kelola Teknologi } \\
\text { Informasi } \\
\text { Mengunakan } \\
\text { Framework Cobit } \\
\text { Dengan Model } \\
\text { Maturity Level } \\
\text { (Studi Kasus } \\
\text { Fakultas ABC) }\end{array}$ & $\begin{array}{l}\text { Tidak difokuskan } \\
\text { pada satu domain }\end{array}$ \\
\hline $\begin{array}{l}\text { (Ambarwati } \\
\text { d1l., 2017) }\end{array}$ & $\begin{array}{l}\text { Analisis } \\
\text { Implementasi } \\
\text { Teknologi } \\
\text { Informasi pada } \\
\text { Domain Deliver } \\
\text { and Support di } \\
\text { PT . RDPI } \\
\end{array}$ & $\begin{array}{l}\text { Cakupan domain } \\
\text { yang luas }\end{array}$ \\
\hline $\begin{array}{l}\text { (Hanief dan } \\
\text { Nugraheni, } \\
\text { 2015) }\end{array}$ & $\begin{array}{l}\text { Pengukuran } \\
\text { Maturity Level } \\
\text { Pembelajaran } \\
\text { Asinkronus } \\
\text { Melalui Media } \\
\text { Tik Dengan } \\
\text { Framework Cobit } \\
4.1\end{array}$ & $\begin{array}{l}\text { Pengukuran } \\
\text { tingkat } \\
\text { kematangan } \\
\text { menggunakan } \\
\text { domain DS7, } \\
\text { DS12, dan DS13 }\end{array}$ \\
\hline $\begin{array}{l}\text { (Muhammad, } \\
\text { 2017) }\end{array}$ & $\begin{array}{l}\text { Pengukuran } \\
\text { Maturity Level } \\
\text { Proses TI AI3 , } \\
\text { Pengukuran } \\
\text { Maturity Level } \\
\text { Proses TI AI3 , } \\
\text { AI4, dan DS4 } \\
\text { Menggunakan } \\
\text { Framework Cobit } \\
4.1 \text {. } \\
\end{array}$ & $\begin{array}{l}\text { Tidak memiliki } \\
\text { grafk radar }\end{array}$ \\
\hline $\begin{array}{l}\text { (Ricoida dan } \\
\text { Hermanto, } \\
\text { 2016) }\end{array}$ & $\begin{array}{l}\text { Tingkat } \\
\text { Kematangan Tata } \\
\text { Kelola Teknologi } \\
\text { Informasi Pada } \\
\text { Layanan } \\
\text { Teknologi Studi } \\
\text { Kasus PT ABC }\end{array}$ & $\begin{array}{l}\text { Menggunakan } \\
\text { DS10 dan DS13 } \\
\text { untuk menilai } \\
\text { tingkat } \\
\text { kematangan }\end{array}$ \\
\hline $\begin{array}{l}\text { (Satyareni dan } \\
\text { Mahanani, } \\
\text { 2014) }\end{array}$ & $\begin{array}{l}\text { Audit Sistem } \\
\text { Informasi } \\
\text { Akademik } \\
\text { Perguruan Tinggi } \\
\text { (PT) XYZ } \\
\text { Menggunakan } \\
\text { Kerangka Kerja } \\
\text { COBIT 4.1 }\end{array}$ & $\begin{array}{l}\text { Maturity level } \\
\text { tiga belas proses } \\
\text { dalam domain } \\
\text { DS }\end{array}$ \\
\hline $\begin{array}{l}\text { Winalia, } \\
\text { Renaldi dan } \\
\text { Hadiana, 2017) }\end{array}$ & $\begin{array}{l}\text { Pengukuran } \\
\text { Tingkat } \\
\text { Kematangan } \\
\text { Teknologi } \\
\text { Informasi } \\
\text { menggunakan } \\
\text { COBIT 4.1 Pada } \\
\text { Universitas } \\
\text { Jenderal Achmad } \\
\text { Yani } \\
\end{array}$ & $\begin{array}{l}\text { Berfokus pada } \\
\text { domain PO dan } \\
\text { menggunakan } \\
\text { kuisioner dalam } \\
\text { perolehan data }\end{array}$ \\
\hline $\begin{array}{l}\text { (Lesmono dan } \\
\text { Erica, 2018) }\end{array}$ & $\begin{array}{l}\text { Tata Kelola } \\
\text { Teknologi } \\
\text { Informasi } \\
\text { Dengan Metode } \\
\text { COBIT 4.1 }\end{array}$ & $\begin{array}{l}\text { Menggunakan } 12 \\
\text { responden dalam } \\
\text { penelitian }\end{array}$ \\
\hline $\begin{array}{l}\text { (Fenny dan } \\
\text { Andry, 2017) }\end{array}$ & $\begin{array}{l}\text { Audit Sistem } \\
\text { Informasi } \\
\text { Menggunakan } \\
\text { Framework } \\
\text { COBIT 4.1 Pada } \\
\text { PT. Aneka Solusi } \\
\text { Teknologi } \\
\end{array}$ & $\begin{array}{l}\text { Tidak memiliki } \\
\text { laporan temuan } \\
\text { dan rekomendasi } \\
\text { untuk studi kasus } \\
\text { tersebut. }\end{array}$ \\
\hline (Kc & $\begin{array}{l}\text { Evaluasi Tingkat } \\
\text { Kematangan } \\
\text { Domain and } \\
\text { Deliver Support } \\
\text { Dengan } \\
\text { Framework } \\
\text { COBIT 4.1 }\end{array}$ & $\begin{array}{l}\text { Hasil dari } \\
\text { penelitian ini } \\
\text { hanya ditujukan } \\
\text { untuk } \\
\text { mengetahui } \\
\begin{array}{l}\text { maturity level } \\
\text { dari tata kelola TI }\end{array}\end{array}$ \\
\hline
\end{tabular}




\begin{tabular}{ccc}
\hline penulis & judul & celah \\
\hline & di & perusahaan \\
& ritel dengan \\
& domain DS5. \\
\hline
\end{tabular}

Berdasarkan penelitian terdahulu pada Tabel 1. Penelitian terdahulu COBIT 4.1 maturity level berpacu pada COBIT, sedangkan ISO/IEC 15504-2 mengacu pada sembilan proses untuk mengetahui capability and performance of process dimension and probability dimension, sehingga tidak relevan dengan objek penelitian karena bukan termasuk dalam proses IT.

\subsection{Pengumpulan Data Penelitian}

Dalam penelitian ini pengumpulan data yang dilakukan dengan pengumpulan data primer yaitu dengan melakukan wawancara dan meminta bukti dokumen jika ada sebagai bukti tambahan kepada pihak - pihak yang terkait dalam penelitian ini, pihak yang terkait adalah layanan akademik dan Kabag Layanan Akademik UISI.

\subsection{Diagram Alur Penelitian}

Dalam diagram alur ini bisa dilihat alur penelitian yang akan dilakukan selama penelitian berlangsung

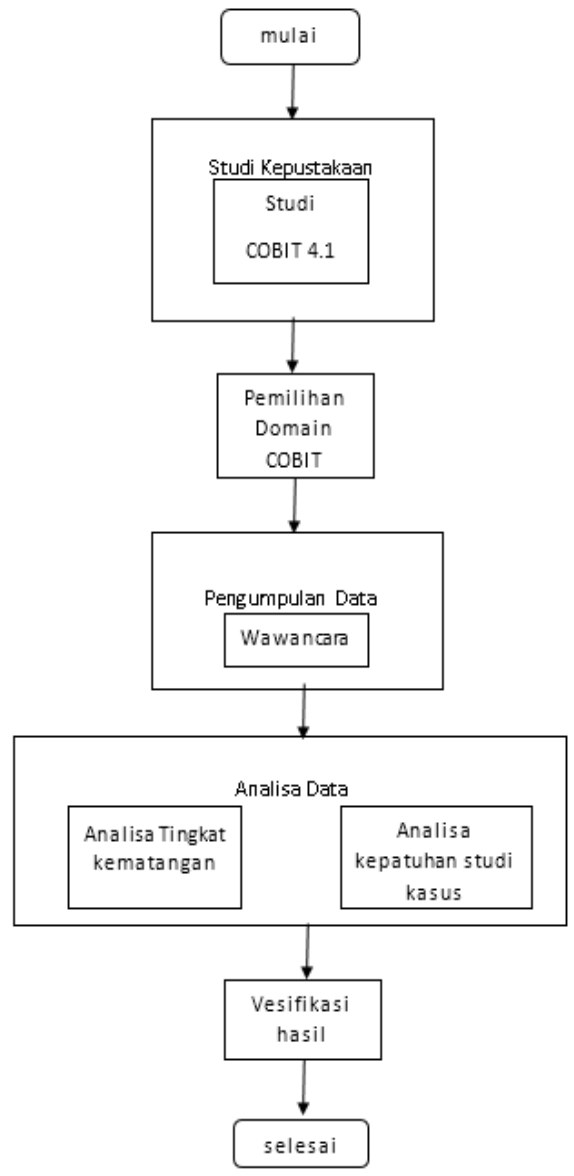

Gambar 1. Diagram Alir Penelitian

Berikut ini adalah penjelasan tentang metode yang digunakan sebagai pengumpulan data : a. Studi literatur : dimana studi yang digunakan sebagai acuan pengerjaaan studi kasus ini adalah COBIT4.1

b. Pemilihan domain COBIT : langkah selanjutnya yaitu pemilihan domain, dimana pemilihan domain ini sangat perlu untuk pemecahan masalah dalam studi kasus yang dipilih, dan domain yang dipilih adalah DS10 tentang Pengelolaan Masalah

c. Pengumpulan data : dalam tahap ini pengumpulan data yang dilakukan adalah dengan melakukan wawancara kepada pihak - pihak yang terkait dalam penelitian, pihak yang terkait adalah layanan akademik UISI

d. Analisis data : pengolahan data yang telah dikumpulkan melalui tahap wawancara yang telah dilakukan

e. Verifikasi : memastikan kembali bahwa data yang diperoleh sudah sama dengan hasil yang didapatkan

f. Strategi perbaikan : pengelompokan data yang perlu diperbaiki dalam studi kasus yang dipilih

g. Rekomendasi : pemberian saran sebagai pelengkap perbaikan yang telah di temukan

\section{HASIL DAN PEMBAHASAN}

Bab ini akan membahas dan perhitungan datadata hasil analisis yang dikumpulkan melalui wawancara pihak layanan akademik dan Kabag Layanan Akademik, yang selanjutnya dianalisis menggunakan DS10 dengan framework COBIT 4.1. Hasil dan pembahasan akan meliputi penentuan dan perhitungan tingkat kematangan dan tingkat kepatuhan layanan akademik. Selanjutnya akan dilakukan pembuatan laporan temuan dan rekomendasi untuk evaluasi terhadap penilaian layanan akademik.

\subsection{Framework Penelitian}

Framework yang digunakan untuk penelitian ini adalah COBIT 4.1 (Control Objective for Information and Related Technology) kumpulan dari dokumen yang dapat membantu kinerja para auditor dimana framework bagi pengelolaan teknologi informasi (TI) dan merupakan kumpulan perangkat yang mendukung manajer untuk menghubungkan antara kebutuhan yang dikendalikan (control requirement), masalah dalam teknis(technical issue), dan risiko bisnis (business risk). COBIT sendiri disusun oleh The IT Governance Institute (ITGI) dan Information System Audit and Control Association (ISACA) (Arumana, 2014).

\subsection{Audit TI}

Audit TI dilakukan pada proses TI, apakah sesuai dengan standart dan ketetapan yang berlaku sehingga audit TI lebih menguji kepatuhan (complience) terhadap prosedur acuan dalam 
pelaksanaan serta terhadap pemangku kepentingan yang terkait (Lusiana, 2018).

\subsection{Identifikasi Proses TI}

Tahap untuk mengidentifikasi proses TI yang akan disesuaikan dengan studi kasus.

Tabel 2. Proses TI dalam studi kasus

\begin{tabular}{lcc}
\hline \multicolumn{2}{c}{ domain ti } & proses ti \\
\hline DS (Deliver & and & DS10 Pengelolaan Masalah \\
Support & & \\
\hline
\end{tabular}

\subsection{Pemilihan Domain COBIT 4.1}

Tahap ini dilakukan untuk pemilihan domain dan menjabarkan apa saja yang dijelaskan dalam subdomain dari DS10 Pengelolaan Masalah.

Tabel 3. Pemilihan domain dan sub domain

\begin{tabular}{cl}
\hline \multicolumn{2}{c}{ DS10 pengelolaan masalah } \\
\hline DS10.1 & $\begin{array}{l}\text { Identifikasi dan klarifikasi } \\
\text { masalah }\end{array}$ \\
DS10.2 & Tracking masalah dan solusi \\
DS10.3 & Penutupan Masalah \\
DS10.4 & Integrasi insiden dan masalah \\
\hline
\end{tabular}

\subsection{Penentuan Skala Audit Checklist}

Melakukan wawancara dengan pihak layanan akademik UISI untuk menjawab pertanyaan pada audit checklist yang telah ditentukan dan menghitung skala masing-masing audit checklist.

Tabel 4. Pemilihan domain dan sub domain

\begin{tabular}{cc}
\hline audit checklist & skala \\
\hline DS10.1.1 & 1 \\
DS10.1.2 & 3 \\
DS10.2.1 & 2 \\
DS10.2.2 & 3 \\
DS10.3.1 & 1 \\
DS10.4.1 & 1 \\
Rata-rata & 1.83 \\
\hline
\end{tabular}

\subsection{Analisis Tingkat Kematangan dan Kepatuhan}

Tahap ini adalah tahap untuk melakukan pengukuran tingkat kematangan dan kepatuhan dari layanan akademik menggunakan domain DS10 dengan framework Cobit 4.1.

Tabel 5 adalah hasil perhitungan tingkat kematangan dan kepatuhan layanan akademik di seluruh proses dalam domain DS10.

Pembobotan dengan jumlah 25\% ini berdasarkan informasi dari direktorat akademik, yang menganggap penggunaan ruang kelas di universitas memiliki prioritas yang sama, sehingga tiap komponen yang ada di DS10 memiliki nilai bobot yang sama.

\begin{tabular}{|c|c|c|c|c|c|}
\hline $\begin{array}{l}\mathbf{n} \\
\mathbf{0}\end{array}$ & proses & $\begin{array}{c}\text { nilai } \\
\text { (n) }\end{array}$ & $\begin{array}{c}\text { bobot } \\
(\%)\end{array}$ & $\begin{array}{c}\text { jumlah } \\
(\mathbf{n x b})\end{array}$ & ref \\
\hline 1 & $\begin{array}{l}\text { Identifikasi } \\
\text { dan } \\
\text { klasifikasi } \\
\text { masalah }\end{array}$ & 2 & $25 \%$ & 0.5 & $\begin{array}{l}\text { DS10. } \\
1\end{array}$ \\
\hline 2 & $\begin{array}{l}\text { Tracking } \\
\text { masalah } \\
\text { dan solusi }\end{array}$ & 2.5 & $25 \%$ & 0.625 & $\begin{array}{l}\text { DS10. } \\
2\end{array}$ \\
\hline 3 & $\begin{array}{l}\text { Penutupan } \\
\text { masalah }\end{array}$ & 1 & $25 \%$ & 0.25 & $\begin{array}{l}\text { DS10. } \\
3\end{array}$ \\
\hline 4 & $\begin{array}{l}\text { Integrasi } \\
\text { insiden dan } \\
\text { masalah }\end{array}$ & 1 & $25 \%$ & 0.25 & $\begin{array}{l}\text { DS10. } \\
4\end{array}$ \\
\hline \multicolumn{2}{|c|}{ Total } & & $100 \%$ & 1.625 & \\
\hline \multicolumn{4}{|c|}{ Nilai Rata-Rata $=($ Total $/ 4)$} & 0.406 & \\
\hline \multicolumn{4}{|c|}{$\begin{array}{l}\text { Nilai Akhir }=(\text { Nilai rata-rata } / 5) \times \\
100 \%\end{array}$} & 8.125 & \\
\hline
\end{tabular}

Dari hasil perhitungan di atas, dapat disimpulkan bahwa hasil yang didapatkan adalah nilai compliance $8.125 \%$ dan maturity level yang berada di tingkat 1 yaitu senilai 1.6. Hal ini menunjukkan bahwa layanan akademik UISI masih belum memanfaatkan TI dengan baik dan secara maksimal.

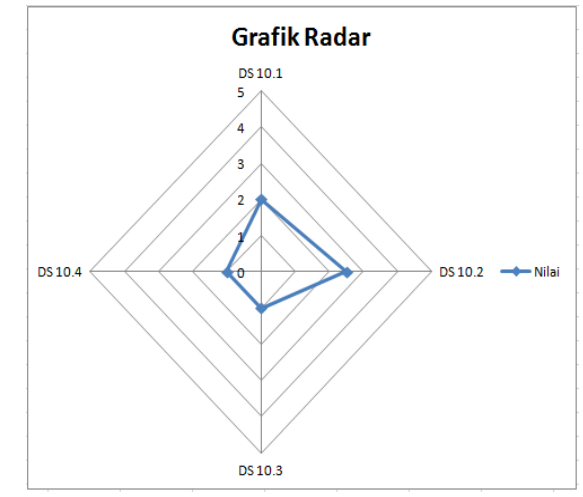

Gambar 2. Grafik radar masing-masing proses DS10.

Dari grafik radar dapat dilihat skala di setiap sub-domain dari DS10 dalam skala 5.

Tabel 6. Hasil tingkat kepatuhan dan kematangan studi kasus DS10 pengelolaan masalah

\begin{tabular}{lc}
\hline Tingkat kepatuhan & $8.125 \%$ \\
Tingkat kematangan & 1.6 \\
\hline
\end{tabular}

\subsection{Temuan dan Rekomendasi}

Setelah melakukan penilaian maka langkah yang dilakukan adalah membuat laporan temuan dan rekomendasi yang ditujukan kepada layanan akademik UISI. Laporan temuan dan rekomendasi berguna untuk keberlangsungan perbaikan untuk layanan akademik UISI. 


\begin{tabular}{cl}
\hline \multicolumn{1}{c}{ temuan } \\
\hline$\bullet \quad \begin{array}{l}\text { Layanan akademik belum memiliki prosedur } \\
\text { untuk pendistribusian ruang kelas }\end{array}$ \\
$\begin{array}{l}\text { Layanan akademik sudah melakukan } \\
\text { pendistribusian ruang kelas sesuai kebutuhan } \\
\text { prodi, dan memiliki bukti. Namun bukti laporan }\end{array}$ \\
$\begin{array}{l}\text { yang dimiliki hanya sebuah jadwal pembagian } \\
\text { kelas, bukan laporan pencatatan. }\end{array}$ \\
\hline $\begin{array}{l}\text { Membuat prosedur untuk pendistribusian } \\
\text { ruang kelas } \\
\text { Membuat laporan yang berisi permintaan dan } \\
\text { pembagian ruang kelas sesuai kebutuhan } \\
\text { prodi }\end{array}$
\end{tabular}

Tabel 8. Tracking Masalah dan Solusi DS10.2

\begin{tabular}{cl}
\hline \multicolumn{1}{c}{ temuan } \\
\hline$\bullet \quad \begin{array}{l}\text { Layanan akademik tidak memiliki dokumen } \\
\text { persetujuan untuk permintaan ruang kelas } \\
\text { Layanan akademik memiliki solusi untuk } \\
\text { menyelesaikan masalah jika ruang kelas penuh, } \\
\text { akan tetapi solusi yang diberikan tidak solutif }\end{array}$ \\
\hline rekomendasi \\
\hline & $\begin{array}{l}\text { Membuat dokumen persetujuan dengan prodi } \\
\text { untuk permintaan ruang kelas } \\
\text { Memberikan solusi yang dapat menyelesaikan } \\
\text { masalah untuk kelas yang penuh dan dapat } \\
\text { dijalankan oleh mahasiswa }\end{array}$ \\
\hline
\end{tabular}

Tabel 9. Penutupan Masalah DS10.3

\section{temuan}

Layanan akademik tidak memberikan status penutupan masalah setelah permasalahan diselesaikan, sehingga pelapor tidak mengerti jika masalah sudah selesai. rekomendasi

Layanan akademik memberikan dan menjelaskan status penutupan masalah kepada pelapor.

Tabel 10. Proses Integrasi Insiden dan Masalah DS10.4

\begin{tabular}{|c|}
\hline temuan \\
\hline $\begin{array}{l}\text { Layanan akademik tidak mengelompokkan antara } \\
\text { insiden dan masalah pendistribusian kelas. }\end{array}$ \\
\hline rekomendasi \\
\hline $\begin{array}{l}\text { Melakukan pengelompokkan terhadap insiden dan } \\
\text { masalah yang sering dialami dalam pendistribusian kelas. }\end{array}$ \\
\hline
\end{tabular}

\section{KESIMPULAN}

Kesimpulan yang dihasilkan dari penelitian diatas adalah :

1. Studi kasus dalam penelitian di layanan akademik UISI dapat diukur tingkat kematangan dan kepatuhannya menggunakan COBIT 4.1 dengan domain DS10.

2. Hasil dari penelitian ini didapat tingkat kematangan 1.6 dari skala 5 yang masih berada pada level 1 yaitu initial/ad hoc.

3. Tingkat kepatuhan di layanan akademik tepatnya di studi kasus pendistribusian ruang kelas sebesar 8.125 persen.

4. Layanan akademik UISI masih belum menggunakan TI dengan efektif untuk proses pendistribusian ruang kelas sehingga memiliki tingkat kematangan yang masih rendah.

\section{UCAPAN TERIMA KASIH}

Penulis mengucapkan banyak terima kasih kepada Allah SWT yang telah memberi nikmat dan kelancaran untuk menyelesaikan penelitian ini. Terima kasih juga penulis ucapkan kepada pihak layanan akademik UISI yang bersedia membantu memberikan informasi yang dibutuhkan, dan tidak lupa penulis berterima kasih kepada dosen pembimbing kuliah Simulasi Tata Kelola dan Audit TI yang membimbing dan memberikan arahan dari awal perkuliahan.

\section{DAFTAR PUSTAKA}

ARUMANA, A., ROCHIM, A. F. \& WINDASARI, I. P., 2014. Analisis Tata Kelola Teknologi Informasi menggunakan Kerangka Kerja COBIT 4.1 pada Fakultas Teknik Undip. Jurnal Teknologi dan SIstem Komputer.

LUSIANA, D., 2018. Mengevaluasi Tingkat Kematangan Domain Delivery Support (DS11) Perpustakaan Menggunakan Kerangka COBIT 4.11. JUSTINDO.

AMBARWATI, A. ET AL. (2017) 'Analisis Implementasi Teknologi Informasi pada Domain Deliver and Support di PT . RDPI', 2(2), pp. 61-66.

FENNY AND ANDRY, J. F. (2017) 'Audit sistem informasi menggunakan framework cobit 4.1 pada pt. aneka solusi teknologi', (November).

HANIEF, S. AND NUGRAHENI, Y. (2015) 'Pengukuran Maturity Level Pembelajaran Asinkronus Melalui Media Tik Dengan Framework Cobit 4.1', pp. 6-8.

KOSASI, S. (2014) 'EVALUASI TINGKAT KEMATANGAN DOMAIN DELIVER AND SUPPORT DENGAN FRAMEWORK COBIT 4 . 1', (372).

LESMONO, I. D. AND ERICA, D. (2018) 'Tata Kelola Teknologi Informasi Dengan Metode COBIT 4 . 1 ( Studi Kasus : PT . IMI )', 18(1).

MUHAMMAD, G. M. (2017) 'Pengukuran Maturity Level Proses TI AI3, Pengukuran Maturity Level Proses TI AI3, AI4, Dan DS4 Menggunakan Framework COBIT 4.1'.

RICOIDA, D. I. AND HERMANTO, D. (2016) 'Tingkat Kematangan Tata Kelola Teknologi Informasi', pp. 6-7.

SATYARENI, D. H. AND MAHANANI, F. (2014) 'Audit Sistem Informasi Akademik Perguruan Tinggi (PT) XYZ Menggunakan Kerangka Kerja COBIT 4.1', Seminar Nasional Aplikasi Teknologi Informasi (SNATI) Yogyakarta, 21(1), pp. 1907-5022.

WARDANI, S. AND PUSPITASARI, M. (2014) 'Audit Tata Kelola Teknologi Informasi 
616 Jurnal Teknologi Informasi dan Ilmu Komputer (JTIIK), Vol. 6, No. 6, Desember 2019, hlm. 611-616

Mengunakan Framework Cobit Dengan Model Maturity Level (Studi Kasus

Fakultas ABC)', 7, pp. 38-46. Available at: http://jurtek.akprind.ac.id/sites/default/files/ 38-46_wardani.pdf.

WINALIA, RENALDI, F. AND HADIANA, A. I. (2017) 'Pengukuran Tingkat Kematangan Teknologi Informasi menggunakan COBIT 4.1 Pada Universitas Jenderal Achmad Yani', pp. 31-36. 